\title{
El estudio de la Isla de Calor Urbana de Superficie del Área Metropolitana de Santiago de Chile con imágenes Terra-MODIS y Análisis de Componentes Principales ${ }^{1}$
}

\author{
Pablo Sarricolea Espinoza ${ }^{2}$ y Javier Martín-Vide ${ }^{3}$
}

\begin{abstract}
RESUMEN
Con el objetivo de conocer los patrones e intensidades de la Isla de Calor Urbana de Superficie (ICUs) de Santiago se han calculado las temperaturas de emisión para 53 imágenes Terra MODIS, se han trazado mapas de intensidad de la ICUS y se ha aplicado Análisis de Componentes Principales. Los resultados muestran que la ICUs tiende a localizar el máximo en las comunas centrales y de Huechuraba y Quilicura, con intensidades superiores a $5^{\circ} \mathrm{C}$. El ACP revela cuatro patrones típicos, que explican el 90,6\% de las situaciones, a saber: ICUs consolidada, ICUs del piedmont y cuña de altos ingresos, un tipo sin ICUs y otra más intensa al sur. De las situaciones sin isla de calor, se ha sugerido la hipótesis de efecto sumidero, asociado a brisa catabática, que barre la ICUs y la desplaza al poniente de la ciudad.
\end{abstract}

Palabras clave: Isla de Calor Urbana de Superficie, efecto sumidero de calor, Terra MODIS, Análisis de Componentes Principales.

\begin{abstract}
In order to understand the patterns and intensities of the Surface Urban Heat Islands (SUHIs) of Santiago emission temperatures were calculated using 53 Terra MODIS satellite images and then factor reduction was performed using Principal Components Analysis (PCA). In addition, intensity maps of SUHIs were created. Results show that the maximum temperature (with intensities measuring above $5^{\circ} \mathrm{C}$ ) within the $\mathrm{SUHI}$ tends to be located in the central municipalities of Santiago, as well as in the municipalities of Huechuraba and Quilicura. Furthermore, PCA reveals four typical patterns, which explain $90.6 \%$ of cases: consolidated SUHI, piedmont SUHI and high income wedge, no SUHI and high intensity SUHI in the south. It has been hypothesized that the lack of a SUHI to the drain effect, which is linked to the katabatic breeze, causing the SUHI to move toward the west sector of the city.
\end{abstract}

Key words: Principal Component Analysis, surface urban heat island, urban heat sink, Terra MODIS

1 Artículo recibido el 3 de agosto de 2012, aceptado el 27 de junio de 2013 y corregido el 20 de octubre de 2013.
2 Departamento de Geografía, Universidad de Chile (Chile). Email: psarricolea@uchilefau.cl

3 Grupo de Climatología, Universidad de Barcelona (España). Email: jmartinvide@ub.edu 
La temperatura superficial es de vital importancia en los estudios de Climatología urbana. Ella, al decir de Voogt y Oke (2003), condiciona y modula la temperatura del aire en las capas más bajas de la atmósfera urbana. Además, es fundamental para estimar los balances energéticos, determinar las condiciones bioclimáticas en el interior de los edificios, y, también, los intercambios térmicos con el entorno, que afectan al confort de los habitantes de la ciudad. En este sentido, Stewart y Oke (2009) proponen áreas homogéneas desde el punto de vista térmico y de diseño urbano, las cuales son, en parte, responsables de la distribución de las temperaturas urbanas.

Para obtener la temperatura superficial se utilizan esencialmente sensores remotos, los cuales registran los valores de temperatura de emisión de las cubiertas de suelo a vista de ojo de pájaro (Oke y Voogt, 1997), permitiendo así conocer su distribución espacial y, en las áreas urbanas, estimar la isla de Calor Urbana de Superficie (ICUs, homóloga a la ICU del aire). Cabe recordar, que la ICUs ha sido estudiada desde el advenimiento de la teledetección, a mediados del siglo XX.

La teledetección ha ampliado las oportunidades en los estudios de Climatología urbana, y también ha significado introducir nuevos conceptos (Voogt \& Oke, 2003). Existe un gran número de sensores remotos útiles para el estudio de la ICUs, tales como Landsat TM y ETM $+{ }^{4}$, NOOA AVHRR, Terra ASTER y Terra MODIS. Los sensores Terra han avanzado más que los demás, pues han suministrado a los investigadores las librerías de emisividad de las diferentes cubiertas terrestres. Además, en el caso de Terra MODIS se poseen subproductos específicos corregidos para el estudio de la temperatura de superficie y su frecuencia de registro es diaria.

Las mediciones tradicionales de la isla de calor han sido mediante pares de estaciones meteorológicas que representan las áreas urbana y rural (Kukla et al., 1986; Karl et al., 1988), o bien, mediante el método de los

\footnotetext{
4 El radiómetro térmico de Landsat ETM+ funcionó entre 1999 y septiembre de 2003.
}

transectos (Johnson, 1985; Torok et al., 2001, Romero et al., 2010a, 2010b). No obstante, existe escasa información de la configuración espacial de las temperaturas en las ciudades, lo cual implica un desafío en cuanto a poseer una mayor cobertura y resolución de las temperaturas urbanas. Es por ello que los estudios de Climatología urbana a alta resolución (espacial) son escasos, y referidos casi en exclusiva a las temperaturas superficiales, es decir, a la ICUs (Streutker, 2003).

Las temperaturas de la superficie son más fáciles de obtener, principalmente por la disponibilidad de productos tales como Terra MODIS, que provee la temperatura de la superficie de la tierra (Land Surface Temperature, LST). Es importante señalar que la relación entre la temperatura del aire y de la superficie no está completamente consensuada, y hay mucha discusión sobre ello. Así, por citar casos extremos, están aquellos que señalan la estrecha y positiva relación entre las temperaturas del aire y de superficie (Arnfield, 2003; Weng, 2009; Nichol, 1994), y otros que se refieren a nulas relaciones entre ellas (Weller y Thorne, 2001). A pesar de lo anteriormente señalado, la Agencia de Protección Ambiental de Estados Unidos (EPA) sugiere que en el caso de las temperaturas nocturnas existe una relación estrecha entre la ICU y la ICUs, hipótesis que se asume. Con ello por ejemplo, se elimina problemas encontrados por Romero et al. (2010a) referidos a sombras diurnas y albedos de las estructuras urbanas.

Múltiples estudios han mencionado explícitamente el potencial y la utilidad del producto MODIS LST en la investigación de la ICUs (Rajasekar y Weng, 2008; Cheval et al., 2009). En particular, las características de realizar observaciones instantáneas, la cobertura mundial y la calidad de los datos de MODIS (Jin y Shepherd, 2005).

Los sensores Terra y Aqua MODIS están operativos desde el año 2000, y sus datos los pueden adquirir gratuitamente investigadores de todo el mundo para sus análisis. Es por esta razón que existe una creciente utilización de ellos, que los valida como una herramienta muy útil para la Climatología urbana (Schwarz et al., 2011 y 2012, Clinton \& Gong, 2013, Hu y Brunsell, 2013). 
No obstante, disponer de una mayor cantidad de datos termométricos implica definir herramientas que permitan sintetizar la información. Y hay desde las más sencillas (mapas promedios) a las más sofisticadas, como el Análisis de Componentes Principales (ACP). Este último adquiere una gran importancia, y tanto en Climatología como en Geografía, posee una amplia y reconocida trayectoria, a diferentes escalas espaciales. Por ejemplo, en estudios de Climatología sinóptica sus aplicaciones se centran en interpretar patrones espaciales diarios de los tipos de circulación atmosférica, facilita realizar catálogos de tipos de tiempo, etc. En Climatología urbana ayuda a resumir las configuraciones típicas y más representativas de la isla de calor, lo cual da carácter climático a los resultados, pues sintetiza información de resolución detallada.

Hasta ahora, el conocimiento de la configuración y la conformación de ICUs en el Área Metropolitana de Santiago es un problema aún no resuelto. Por ejemplo, no se conocen los patrones espaciales típicos de ICUs, muy importantes para proponer medidas de mitigación, o las intensidades más habituales de ella. Por ello, este artículo responde a dichas interrogantes.

\section{Materiales y métodos}

El área de estudio corresponde al área metropolitana de Santiago. Ella es la capital económica, demográfica, industrial, comercial y financiera de Chile, además de ser la capital de la Región Metropolitana. Posee como región una superficie de 15.403,2km², es la más pequeña de todas las regiones del país, pero en la que habitan más personas, con una población superior a los 7 millones de habitantes, siendo así la región más densamente ocupada. Su clima es de tipo "mediterráneo continental", el cual presenta una estación seca prolongada e inviernos Iluviosos. Según la clasificación de Köppen presenta un clima templado de verano seco (Csb). Respecto a las temperaturas extremas para el período de referencia 1981-2010, el mes de enero alcanza $30,1^{\circ} \mathrm{C}$ como temperatura media de las máximas, mientras que julio registra una media de las mínimas de unos $3,9^{\circ} \mathrm{C}$, lo cual implica una oscilación térmica de $26,2^{\circ} \mathrm{C}$. La temperatura media anual es de $14,7^{\circ} \mathrm{C}$, enero es el mes más cálido, con una temperatura media de $21,2^{\circ} \mathrm{C}$, y el mes más frío corresponde a julio con $8,2^{\circ} \mathrm{C}$, siendo la amplitud térmica media de unos $13^{\circ} \mathrm{C}$.

Al tratarse de un estudio de Climatología urbana, delimitaremos el área adyacente a la ciudad de Santiago (que puede corresponder a un área de influencia climática de la ciudad). Esta área colindante a la ciudad está compuesta por paisajes agrarios, naturales y seminaturales. Para demarcar el límite de esta área de influencia o similar a la ciudad, se definen los siguientes criterios:

1. Que la altitud se encuentre entre los 400 y los 1.150 m.s.n.m. Esta condición deja fuera una parte del núcleo urbano de Peñaflor y un pequeño sector de Lo Barnechea.

2. Que las pendientes sean inferiores a $16,7^{\circ}(30 \%)$, lo cual permite eliminar áreas que no están urbanizadas y sometidas a una insolación diferente al área metropolitana de Santiago. Con ello, se quedan fuera del estudio el cordón los Ratones, cerro Chena, Aguirre, Colorado, Renca, San Ignacio, La Región, San Cristóbal, Los Cordones y Quilhuica, entre otras de menor tamaño.

Con ello se generó un área de estudio que cubre 42 comunas y una superficie cercana a las 190.000 hectáreas, de la cual casi un tercio se encuentra urbanizada.

Se utilizan 53 imágenes Terra MODIS adquiridas desde el servidor de imágenes Global Visualization Viewer del Servicio Geológico de los Estados Unidos (United States Geological Survey), disponible en http:// glovis.usgs.gov/. En dicho servidor, se dispone de una amplia colección de productos de imágenes de satélite. Para efectos de este artículo, se utilizó el producto MOD11A1, en su versión 5.0.

El producto MOD11A1 corresponde a imágenes de temperatura de emisión de superficie, en este caso a resolución diaria y a una hora nocturna (23:59 p.m.). Un importante aspecto, e imprescindible, fue que las noches fuesen despejadas, pues no existe ningún algoritmo capaz de eliminar la nubosidad y rescatar en superficie los datos 
de temperatura. Las imágenes poseen una proyección sinusoidal, y cubren un área de aproximadamente 1.100 × 1.100 kilómetros (latitud y longitud). Además, las imágenes ya vienen corregidas, por lo tanto, este producto está listo para su uso en aplicaciones científicas y publicaciones. El formato de los datos es HDF-EOS (Hierarchical Data Format - Earth Observing System o Formato de Datos Jerárquicos que se aplica al Sistema de Observación de la Tierra). Además, dispone de varias capas de información, entre las que encontramos la temperatura de superficie nocturna. En ella se indica la forma de almacenar los datos (16 bit) y el factor de conversión a Kelvin $(0,02)$; por lo tanto, para cada una de nuestras imágenes multiplicamos los valores digitales de cada píxel por 0,02 y posteriormente restamos 273,15, quedando la temperatura en grados Celsius.
Cabe destacar que el producto MOD11A1 versión 5 posee correcciones topográficas, de transparencia atmosférica, remoción de nubes que contaminan el cálculo de la temperatura y un error menor de $1 \mathrm{~K}$ en imágenes sin cubierta nubosa (Wan, 2007).

Las imágenes fueron recortadas en función del límite del área de estudio, quedando cada una con 1.800 píxeles. Para que ellas fueran comparables, se estandarizaron empleando los puntajes Z. Así, se obtuvo el valor medio de cada imagen recortada $(\mu)$ y su desviación estándar $(\sigma)$, los cuales se aprecian en el Cuadro $N^{\circ} 1$. Con dichos parámetros de la distribución normal, se aplicó para cada píxel (X) la siguiente operación:

$$
Z=(X-\mu) / \sigma
$$

Cuadro $\mathrm{N}^{\circ} 1$

Media y desviación estándar de las imágenes Terra MODIS analizadas

\begin{tabular}{|l|c|r|r|l|l|r|r|}
\hline Fecha & Día & $\begin{array}{c}\text { Media } \\
\left({ }^{\circ} \mathrm{C}\right)\end{array}$ & $\begin{array}{c}\text { Desv. } \\
\text { Est. }\left({ }^{\circ} \mathrm{C}\right)\end{array}$ & \multicolumn{1}{c|}{ Fecha } & Día & $\begin{array}{c}\text { Media } \\
\left({ }^{\circ} \mathrm{C}\right)\end{array}$ & $\begin{array}{c}\text { Desv. } \\
\text { Est. }\left({ }^{\circ} \mathrm{C}\right)\end{array}$ \\
\hline 4 de enero & Lunes & 14,87 & 1,24 & 8 de mayo & Sábado & 6,44 & 1,10 \\
\hline 8 de enero & Viernes & 15,66 & 1,59 & 5 de junio & Sábado & 3,09 & 1,47 \\
\hline 9 de enero & Sábado & 15,77 & 1,74 & 6 de junio & Domingo & 3,31 & 1,72 \\
\hline 10 de enero & Domingo & 17,34 & 1,74 & 25 de junio & Viernes & 2,56 & 0,92 \\
\hline 11 de enero & Lunes & 13,69 & 1,72 & 27 de junio & Domingo & 0,18 & 0,90 \\
\hline 13 de enero & Miércoles & 15,11 & 1,75 & 28 de junio & Lunes & 0,34 & 1,09 \\
\hline 21 de enero & Jueves & 21,36 & 1,81 & 29 de junio & Martes & 1,47 & 1,15 \\
\hline 22 de enero & Viernes & 18,59 & 1,85 & 18 de julio & Domingo & $-1,34$ & 0,93 \\
\hline 23 de enero & Sábado & 18,58 & 1,37 & 20 de agosto & Viernes & 6,40 & 1,64 \\
\hline 2 de febrero & Martes & 16,76 & 1,79 & 25 de agosto & Miércoles & 4,91 & 1,24 \\
\hline 9 de febrero & Martes & 18,12 & 1,67 & 5 de septiembre & Domingo & 5,78 & 1,14 \\
\hline 10 de febrero & Miércoles & 16,71 & 1,65 & 2 de octubre & Sábado & 6,63 & 1,56 \\
\hline 21 de febrero & Domingo & 15,79 & 1,59 & 25 de noviembre & Jueves & 12,66 & 1,25 \\
\hline 24 de febrero & Miércoles & 15,53 & 1,46 & 5 de diciembre & Domingo & 13,97 & 1,33 \\
\hline 9 de marzo & Martes & 14,48 & 1,62 & 8 de diciembre & Miércoles & 13,54 & 1,34 \\
\hline 10 de marzo & Miércoles & 15,50 & 1,89 & 9 de diciembre & Jueves & 12,15 & 1,37 \\
\hline 15 de marzo & Lunes & 15,45 & 1,47 & 13 de diciembre & Lunes & 10,05 & 1,53 \\
\hline
\end{tabular}



Metropolitana de Santiago de Chile con imÁgenes Terra-MODiS Y ANÁlisis de COMPONENTES PRINCIPALES

Continuación Cuadro $N^{\circ} 1$

\begin{tabular}{|l|c|r|r|l|l|r|r|}
\hline Fecha & Día & $\begin{array}{c}\text { Media } \\
\left({ }^{\circ} \mathrm{C}\right)\end{array}$ & $\begin{array}{c}\text { Desv. } \\
\text { Est. }\left({ }^{\circ} \mathrm{C}\right)\end{array}$ & Fecha & Día & $\begin{array}{c}\text { Media } \\
\left({ }^{\circ} \mathrm{C}\right)\end{array}$ & $\begin{array}{c}\text { Desv. } \\
\text { Est. }\left({ }^{\circ} \mathrm{C}\right)\end{array}$ \\
\hline 16 de marzo & Martes & 14,34 & 1,87 & 14 de diciembre & Martes & 14,54 & 1,35 \\
\hline 20 de marzo & Sábado & 15,16 & 1,55 & 16 de diciembre & Jueves & 14,35 & 0,98 \\
\hline 24 de marzo & Miércoles & 13,91 & 1,89 & 19 de diciembre & Domingo & 13,46 & 1,27 \\
\hline 26 de marzo & Viernes & 15,70 & 1,74 & 20 de diciembre & Lunes & 13,78 & 1,56 \\
\hline 3 de abril & Sábado & 12,02 & 1,76 & 21 de diciembre & Martes & 16,97 & 1,64 \\
\hline 4 de abril & Domingo & 12,57 & 1,94 & 22 de diciembre & Miércoles & 15,76 & 1,56 \\
\hline 5 de abril & Lunes & 12,28 & 2,05 & 24 de diciembre & Viernes & 14,13 & 1,10 \\
\hline 14 de abril & Miércoles & 8,73 & 2,05 & 25 de diciembre & Sábado & 16,62 & 1,24 \\
\hline 15 de abril & Jueves & 9,08 & 1,94 & 26 de diciembre & Domingo & 15,96 & 1,45 \\
\hline 22 de abril & Jueves & 5,51 & 1,46 & & & & \\
\hline
\end{tabular}

Fuente: Elaboración propia.

De este modo, cabe destacar que dos tercios de las imágenes son de día laboral (35 imágenes, que representan el $66 \%$ del total), tal como se aprecia en la Figura $N^{0} 1$, y que, además, el reparto estacional de ellas indica, 24 imágenes de verano, 11 de otoño, 8 de invierno y 10 de primavera.

Para simplificar los diversos mapas y registros de temperatura de las imágenes Terra MODIS, se construyeron tres conjuntos de mapas y gráficos:
Mapas de las diferencias térmicas, restando en cada mapa el valor de un píxel considerado representativo de las temperaturas no urbanas, que en este caso fue Pirque. En total se obtienen 5 mapas (uno anual y cuatro de las estaciones).

Mapas promedios de las temperaturas estandarizadas, tanto anual como de cada estación, obteniéndose 5 mapas, los cuales están mejorados en resolución mediante interpolación geoestadística Kriging ordinario.

Figura $\mathrm{N}^{\circ} 1$

Distribución porcentual, según el día de la semana y la estación del año de las imágenes trabajadas.

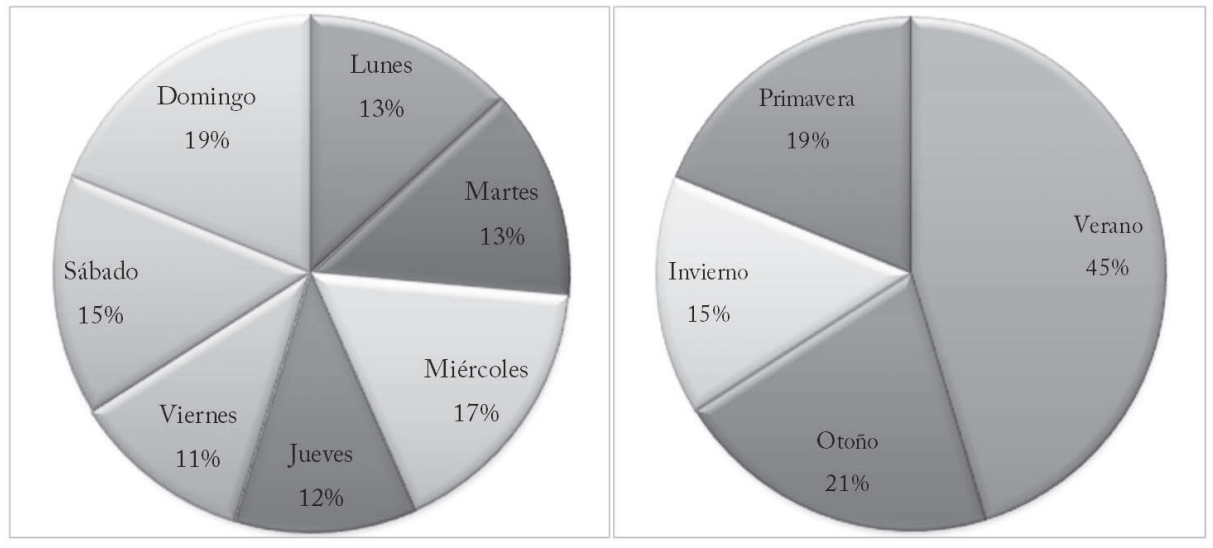

Fuente: Elaboración propia. 
Cuatro mapas del análisis de componentes principales con rotación Varimax.

\section{Resultados termométricos y mapas de diferencias térmicas}

De manera agregada se calculan los valores de las temperaturas urbanas y rurales, y para las 4 estaciones del año (ver Figura № 2). La ciudad de Santiago es siempre más cálida que su entorno rural, con intensidades promedio de la ICUs de $0,8^{\circ} \mathrm{C}$ en invierno, $1,5^{\circ} \mathrm{C}$ en primavera, $1,9^{\circ} \mathrm{C}$ en verano y $2^{\circ} \mathrm{C}$ en otoño.

Figura $N^{\circ} 2$

Temperaturas promedio y diferencias térmicas entre áreas urbanas y rurales según estaciones del año

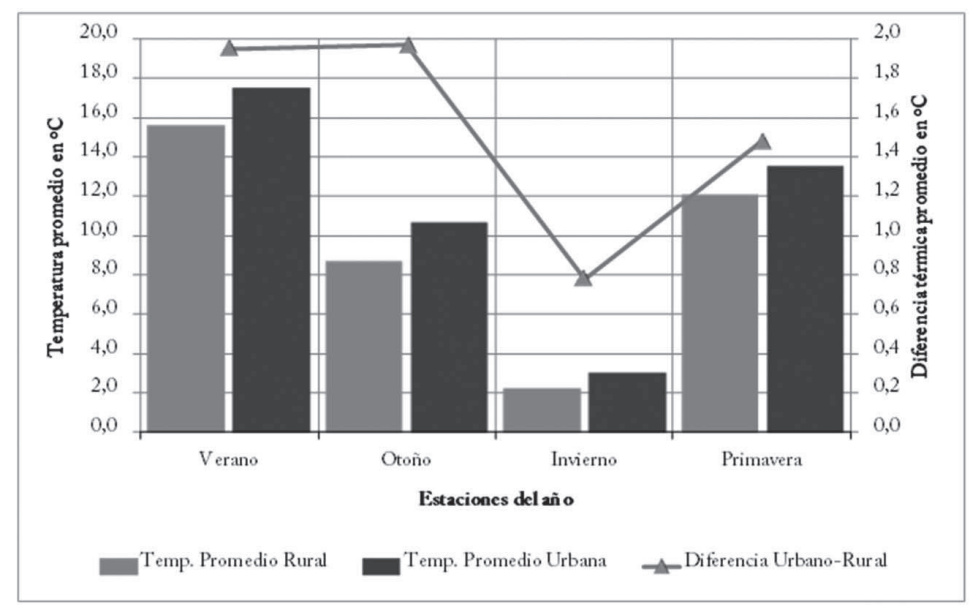

Fuente: Elaboración propia.

También se ha calculado la ICUs considerando como área rural los valores termométricos de Pirque, y una agregación comunal de las temperaturas de superficie. Se ha obtenido que las comunas más cálidas (por encima de $3{ }^{\circ} \mathrm{C}$ ) corresponden a Providencia, Ñuñoa, Santiago, Independencia, Conchalí, Huechu- raba y Estación Central. Las comunas más frescas son Pirque, Lampa, Peñaflor, Calera de Tango y Paine, que son periféricas (Cuadro $N^{\circ} 2$ ). A nivel estacional y anual la Tabla $N^{\circ} 2$ muestra la intensidad media de la ICUs según comuna.

\section{Cuadro $\mathrm{N}^{\circ} 2$}

Resumen estadístico de la ICUs promedio a nivel comunal, tanto anual como estacional

\begin{tabular}{|l|r|r|r|r|r|}
\hline Comuna & ICUs Verano & ICUs Otoño & ICUs Invierno & $\begin{array}{c}\text { ICUs } \\
\text { Primavera }\end{array}$ & ICUs anual \\
\hline Providencia & 4,39 & 4,95 & 3,35 & 4,14 & 4,21 \\
\hline Nuñoa & 3,97 & 3,92 & 2,36 & 3,59 & 3,46 \\
\hline Santiago & 3,90 & 4,04 & 2,08 & 3,53 & 3,39 \\
\hline Independencia & 3,88 & 3,70 & 1,46 & 3,41 & 3,11 \\
\hline
\end{tabular}


El estudio de la isla de Calor Urbana de Superficie del Área Metropolitana de Santiago de Chile con imágenes Terra-MODis Y ANÁlisis de COMPONENTES PRINCIPAleS

Continuación Cuadro $\mathrm{N}^{\circ} 2$

\begin{tabular}{|c|c|c|c|c|c|}
\hline Comuna & ICUs Verano & ICUs Otoño & ICUs Invierno & $\begin{array}{c}\mathrm{ICUs} \\
\text { Primavera }\end{array}$ & ICUs anual \\
\hline Conchalí & 3,77 & 3,43 & 1,59 & 3,46 & 3,06 \\
\hline Huechuraba & 3,43 & 3,43 & 2,18 & 3,19 & 3,06 \\
\hline Estación Central & 3,68 & 3,29 & 1,60 & 3,44 & 3,00 \\
\hline Recoleta & 3,66 & 3,51 & 1,54 & 3,18 & 2,97 \\
\hline Las Condes & 3,14 & 3,66 & 2,21 & 2,80 & 2,95 \\
\hline San Miguel & 3,54 & 3,32 & 1,48 & 3,07 & 2,85 \\
\hline Quinta Normal & 3,59 & 3,25 & 1,33 & 3,23 & 2,85 \\
\hline Renca & 3,39 & 3,03 & 1,66 & 3,28 & 2,84 \\
\hline Pedro Aguirre Cerda & 3,53 & 3,12 & 1,57 & 3,11 & 2,83 \\
\hline Vitacura & 2,84 & 3,33 & 2,32 & 2,53 & 2,76 \\
\hline Cerrillos & 3,49 & 2,93 & 1,44 & 3,09 & 2,74 \\
\hline Macul & 3,37 & 3,02 & 1,33 & 2,98 & 2,68 \\
\hline Lo Prado & 3,40 & 2,85 & 1,05 & 3,14 & 2,61 \\
\hline La Reina & 2,87 & 3,19 & 1,84 & 2,42 & 2,58 \\
\hline San Joaquín & 3,32 & 3,04 & 1,05 & 2,85 & 2,57 \\
\hline La Cisterna & 3,12 & 2,98 & 1,22 & 2,81 & 2,53 \\
\hline Lo Espejo & 3,14 & 2,83 & 0,99 & 2,71 & 2,42 \\
\hline Peñalolén & 2,71 & 3,01 & 1,26 & 2,14 & 2,28 \\
\hline Cerro Navia & 3,04 & 2,39 & 0,68 & 2,92 & 2,26 \\
\hline La Florida & 2,77 & 2,72 & 1,10 & 2,22 & 2,20 \\
\hline La Granja & 2,82 & 2,61 & 0,72 & 2,32 & 2,12 \\
\hline Quilicura & 2,68 & 2,09 & 0,88 & 2,77 & 2,11 \\
\hline El Bosque & 2,67 & 2,53 & 0,75 & 2,39 & 2,08 \\
\hline San Ramón & 2,72 & 2,54 & 0,55 & 2,21 & 2,01 \\
\hline Maipú & 2,13 & 1,84 & 0,99 & 2,35 & 1,83 \\
\hline Lo Barnechea & 1,67 & 2,48 & 1,14 & 1,19 & 1,62 \\
\hline Puente Alto & 1,91 & 2,07 & 0,84 & 1,49 & 1,58 \\
\hline San Bernardo & 1,59 & 1,55 & 0,91 & 1,90 & 1,49 \\
\hline Colina & 1,73 & 1,46 & 0,79 & 1,76 & 1,44 \\
\hline Padre Hurtado & 1,04 & 1,15 & 1,44 & 1,82 & 1,36 \\
\hline La Pintana & 1,56 & 1,30 & 0,28 & 1,46 & 1,15 \\
\hline Pudahuel & 1,60 & 0,74 & $-0,02$ & 1,73 & 1,01 \\
\hline Buin & 0,94 & 0,81 & 0,69 & 1,40 & 0,96 \\
\hline Paine & 0,61 & 0,72 & 0,86 & 1,03 & 0,81 \\
\hline Calera de Tango & 0,30 & 0,56 & 1,00 & 1,03 & 0,72 \\
\hline Peñaflor & 0,14 & $-0,04$ & 0,91 & 0,81 & 0,45 \\
\hline Lampa & 0,30 & $-0,05$ & $-0,10$ & 0,56 & 0,18 \\
\hline Pirque & 0,00 & 0,00 & 0,00 & 0,00 & 0,00 \\
\hline
\end{tabular}

Fuente: Elaboración propia.

Con el Cuadro $N^{\circ} 2$ se investigó sobre las relaciones entre las intensidades de la ICUs y las estaciones, encontrándose que todas se relacionan con una alta significancia estadís- 
tica ( $p$-value menor a 0,05 o nivel de confianza mayor de 95\%). No obstante, el invierno posee coeficientes de correlación de Pearson (r) entre 0,66 con verano y 0,79 con otoño, mientras que los otros están correlacionados con un «r» mayor a 0,91. Se ha cartografiado la ICUs promedio anual y de estaciones en mapas que expresan las diferencias térmicas urbano-rural. Ello se realizó restando el valor térmico mínimo, el cual está localizado en Pirque (un mismo píxel para todos las imágenes Terra MODIS), quedando así seleccionado como representante del área rural.

Las Figuras $\mathrm{N}^{\circ} 3$ y $\mathrm{N}^{\circ} 4$ indican que la intensidad de la isla de calor urbana de superficie (al considerar cero en el punto de Pirque) es de mayor magnitud durante el otoño $\left(7,4^{\circ} \mathrm{C}\right)$, seguida de verano $\left(5,9^{\circ} \mathrm{C}\right)$, primavera $\left(5,4^{\circ} \mathrm{C}\right)$ e invierno $\left(5,0^{\circ} \mathrm{C}\right)$. Los mapas indican que las estaciones de mayor intensidad de la isla de calor son otoño y verano, con diferencias térmicas superiores a $\operatorname{los} 4,6^{\circ} \mathrm{C}$ respecto a su periferia, e incluso llegando a los $7^{\circ} \mathrm{C}$ en la zona oriente de mayor densidad construida; mientras que en invierno y primavera la ICUs es de menor tamaño, y circunscrita al oriente de la capital y la zona industrial de Quilicura.

Las laderas del sector norte del área de estudio parecen desempeñar un importante rol en las temperaturas nocturnas, pues se muestran más cálidas que los fondos de valle, y con temperaturas similares al centro de la ciudad.

Anualmente (Figura $N^{\circ} 5$ ), los patrones confirman que la zona oriente de la ciudad y las laderas del sector norte acumulan la mayor temperatura, con lo cual, la ICUs anual supera en Santiago los $5,5^{\circ} \mathrm{C}$.

Figura $\mathrm{N}^{\circ} 3$

Mapas de la isla de calor urbana de Santiago de Chile (verano y otoño)
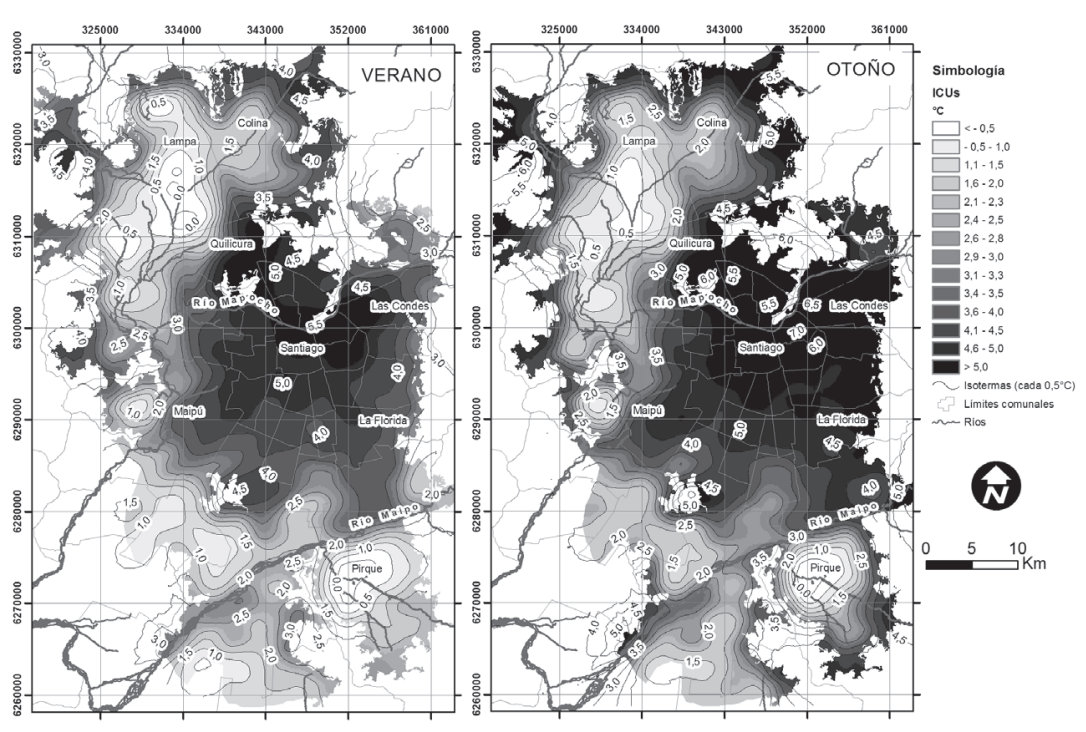

Fuente: Elaboración propia. 
Figura $\mathrm{N}^{\circ} 4$

Mapas de la isla de calor urbana de Santiago de Chile (invierno y primavera)
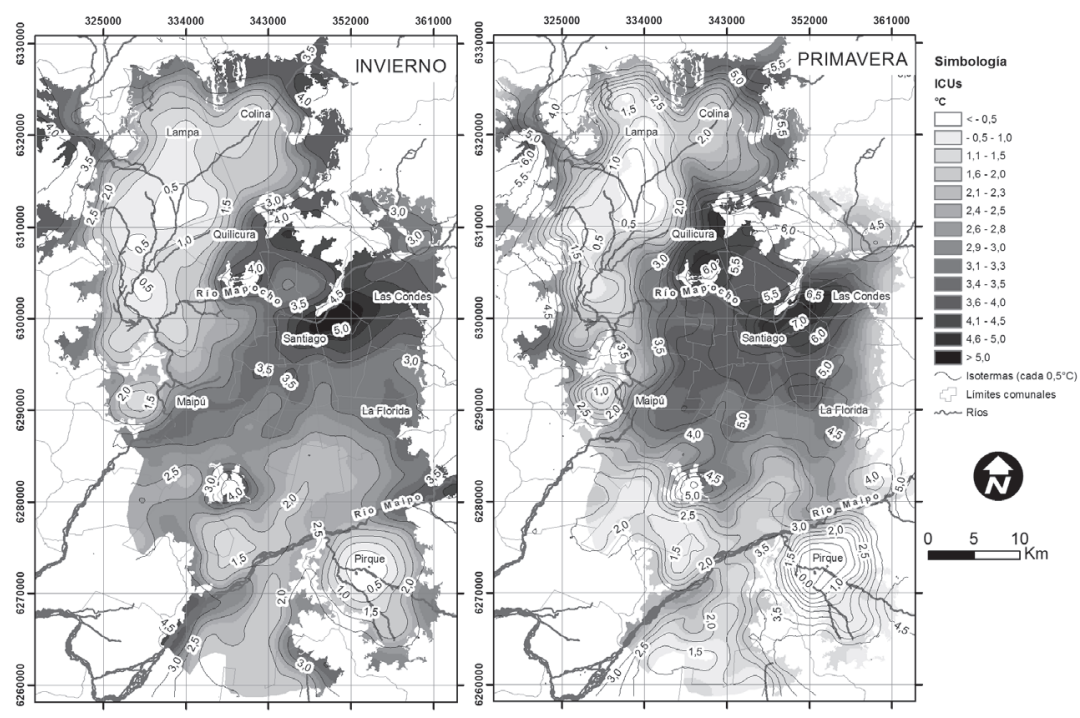

Fuente: Elaboración propia.

Figura $\mathrm{N}^{\circ} 5$.

Mapas anuales de la isla de calor urbana de Santiago de Chile.
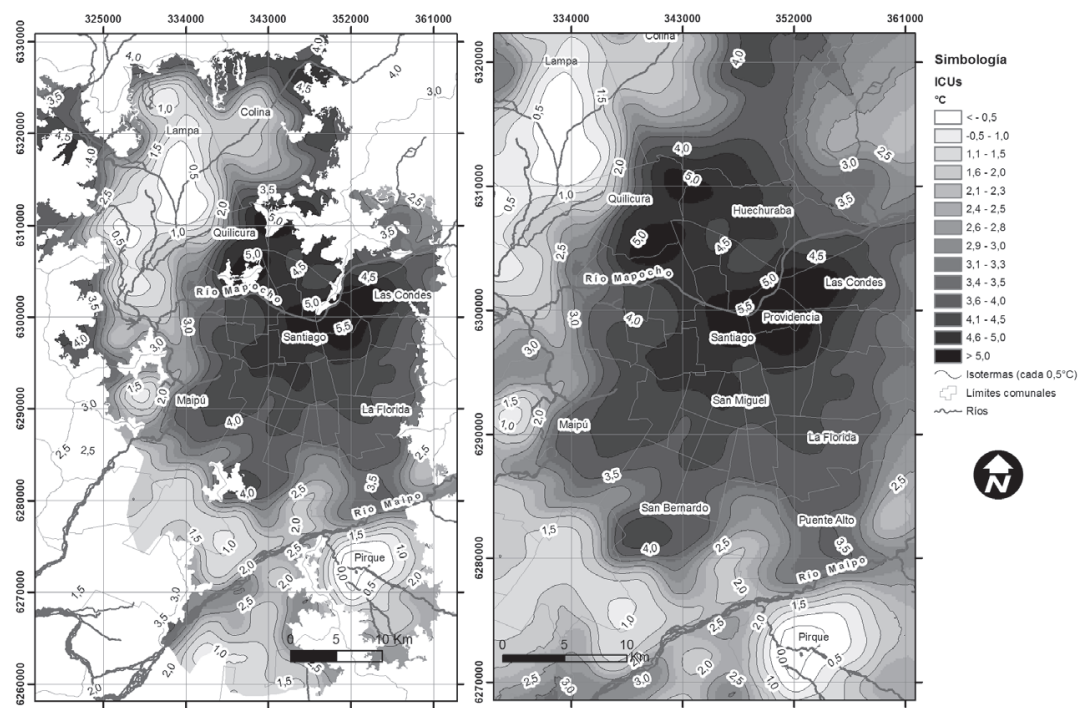

Fuente: Elaboración propia.

\section{Síntesis del análisis de los mapas estandarizados}

Los mapas estandarizados de las temperaturas de superficie fueron promediados para cada estación del año (verano, otoño, invierno y primavera), además de uno anual. Todos ellos muestran que la isla de calor tiende a localizar el máximo térmico en las comunas de Santiago, Providencia, Las Condes, Ñuñoa y Vitacura, conformando un núcleo cálido 
asociado a la mayor densidad construida. Además, las comunas de Huechuraba y Quilicura conforman otro núcleo cálido, el que está asociado a viviendas de alto nivel de ingresos en el primer caso e industrias en el caso de Quilicura.

El lector advertirá al observar las figuras promedio estandarizadas de las temperaturas superficiales nocturnas que la periferia de la ciudad es generalmente fría, lo cual resulta del efecto isla de calor. No obstante, se debe matizar tres singularidades interesantes:

Por un lado, el río Maipo en el límite de las comunas de Buin y San Bernardo es, durante todo el año, más cálido que su entorno (Figuras $\mathrm{N}^{\circ} 6$ a 8), siendo incluso el fenómeno más acusado en invierno. Esto se explica por las propiedades térmicas del agua, la cual posee una alta capacidad de almacenar calor y una elevada inercia térmica. Este fenómeno también es apreciable, aunque en menor proporción, en el río Mapocho, cerca de la comuna de Padre Hurtado.

La zona norte del área estudiada, es decir, Lampa y Colina, presentan en sus terrenos más elevados (sin superar los 1.150 m.s.n.m fijados), tanto en las faldas de la cordillera de la Costa como en los cordones de Chicureo, una superficie recalentada, lo cual puede deberse a flujos nocturnos de montaña-valle de carácter catabático. Esto genera una franja que a las 0:00 a.m. es más cálida que los fondos de valle, los cuales se presentan tan fríos como muestran los registros de Pirque y Buin (incluso en Puente Alto es notorio). Lo anteriormente señalado es más intenso en otoño e invierno (Figuras $\mathrm{N}^{\circ} 6$ a 8 ).

Una evidente vaguada térmica que ingresa a la ciudad desde la comuna de La Pintana, la cual posee población de bajo nivel socioeconómico, alcanzando incluso parte de las comunas de La Florida y La Granja en invierno (Figuras $\mathrm{N}^{\circ} 6$ a $\mathrm{N}^{\circ} 8$ ). Además, la cuña es poco perceptible en primavera, debido a las aguas frías de fusión del Maipo.

Salvando estas tres peculiaridades, los resultados indican una clara isla de calor urbana de superficie, con dos núcleos principales de mayor nivel térmico. Asimismo, ella se manifiesta durante todo el año.

Figura $\mathrm{N}^{\circ} 6$

Mapas promedio estandarizados de las temperaturas de verano y otoño
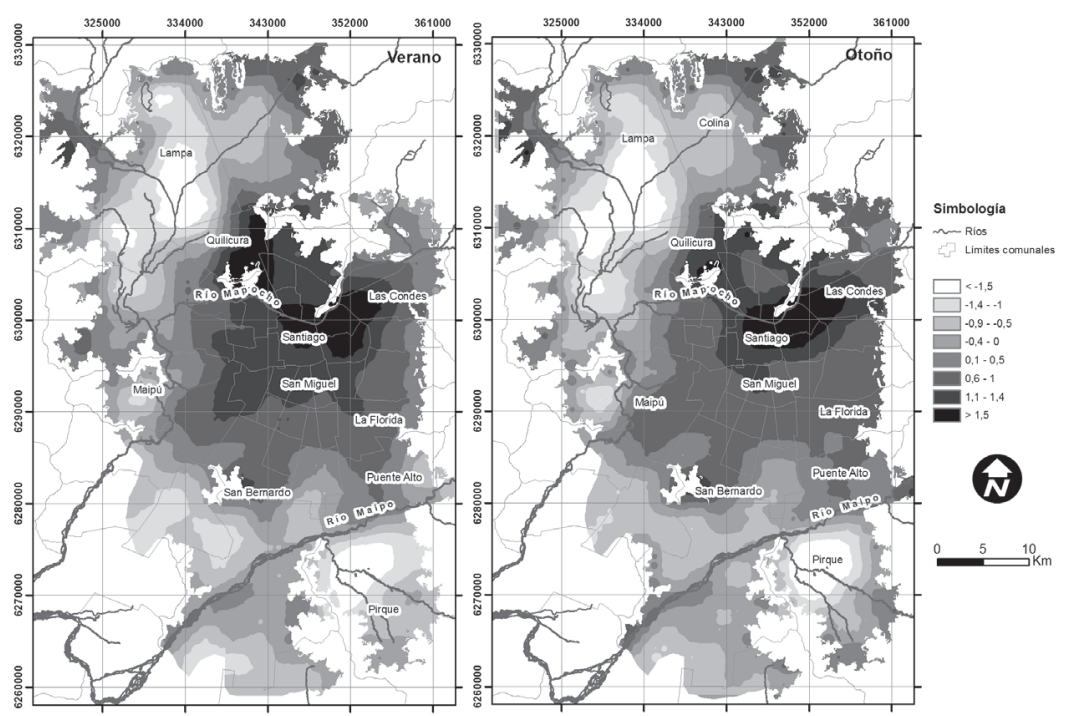

Fuente: Elaboración propia. 
Figura $\mathrm{N}^{\circ} 7$

Mapas promedio estandarizados de las temperaturas de invierno y primavera
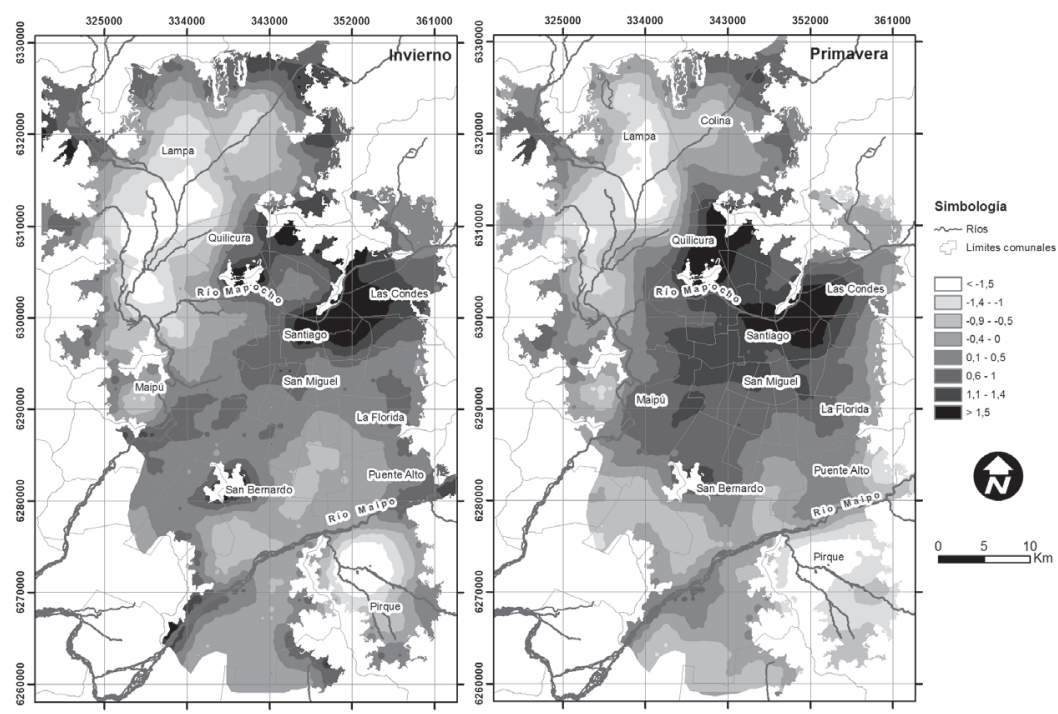

Fuente: Elaboración propia.

Figura $\mathrm{N}^{\circ} 8$

Mapa promedio estandarizado de las temperaturas anuales

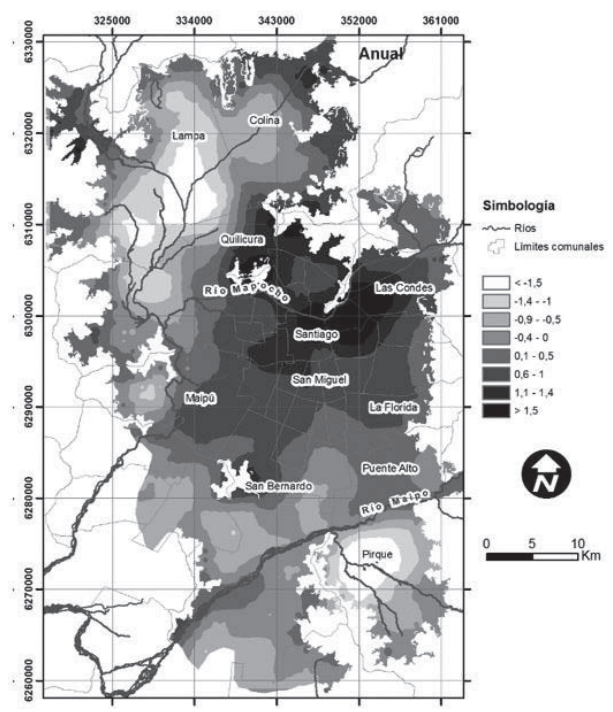

Fuente: Elaboración propia.

\section{Síntesis del Análisis de Componentes Principales de los mapas estandarizados}

Con el propósito de conocer los patrones típicos que adquiere la isla de calor se optó, además de construir los mapas de promedios, por realizar un análisis de componentes principales. Esta técnica permite resumir las 53 imágenes en nuevos factores complejos que explican gran parte de la varianza, y posibilita interpretar los patrones espaciales asociados a ellos. 
En primer lugar, se generó la matriz de correlación de las imágenes, y con ello se consiguió detectar días con baja, moderada, acusada y muy acusada correlación. Los días comprendidos entre el 5 de junio y el 2 de octubre (a excepción del 25 de agosto) no se relacionan con el resto de los días del año; al igual que las imágenes del 21 de enero y el 13 de diciembre. Todas ellas poseen una configuración de los máximos de temperatura localizados al sur y poniente del área Metropolitana de Santiago de Chile, desde Buin hasta Pudahuel. El resto de los días está altamente correlacionado, y muestra patrones más concéntricos a las comunas de Santiago y Providencia.

Luego de obtener las correlaciones entre las imágenes se ha estimado la comunalidad $\left(h^{2}\right)$ por el cuadrado del coeficiente de correlación múltiple entre $\mathrm{x}$ y las demás variable. Ellas explican el peso de cada uno de los días en la varianza explicada. En general los valores son mayores a 0,8. No obstante, hay tres días que no superan dicho valor, los cuales corresponden a situaciones de invierno (25 y 27 de junio y 18 de julio). En dichos casos, la configuración sinóptica de la topografía de 500 hPa muestra un bajo índice de circulación zonal del oeste, con vaguada polar y una depresión aislada en niveles altos (DANA), desplazando la isla de calor más al norte de la ciudad. Las mayores comunalidades (iguales o superiores a 0,97) corresponden a 6 casos, centrados entre verano y otoño, siendo los de los días 22 de enero, 21 y 24 de febrero, 10 y 16 de marzo y 4 de abril.

Comprobadas las comunalidades se establece el número de componentes principales. El Cuadro $N^{\circ} 3$ resume para las 10 primeras componentes la distribución de la varianza total explicada mediante ACP. En ella se aprecia que luego de rotar la matriz con el método Varimax (Kaiser, 1958) y aplicando la regla de Kaiser (1960), es decir, conservando aquellos factores cuyos valores propios o eigenvalues sean mayores a 1 , y el criterio del «scree graph» (Cattell, 1966), basta con 4 factores para explicar el $90,7 \%$ de la varianza total. Así, el componente 1 rotado explica el $44,5 \%$ de la varianza total, el componente 2 , un $22,2 \%$, el 3 , un $20,2 \%$ y, finalmente, el componente 4 , un $3,6 \%$.

Cuadro $\mathrm{N}^{\circ} 3$

Varianza explicada del $\mathrm{ACP}$, rotadas con el método varimax.

\begin{tabular}{|c|c|c|c|c|c|c|c|c|c|}
\hline \multirow{2}{*}{ Comp. } & \multicolumn{3}{|c|}{ Autovalores iniciales } & \multicolumn{3}{|c|}{$\begin{array}{c}\text { Sumas de las saturaciones al } \\
\text { cuadrado de la extracción }\end{array}$} & \multicolumn{3}{|c|}{$\begin{array}{c}\text { Suma de las saturaciones al } \\
\text { cuadrado de la rotación }\end{array}$} \\
\hline & Total & $\begin{array}{c}\% \text { de la } \\
\text { varianza }\end{array}$ & $\begin{array}{c}\% \\
\text { acumulado } \\
\end{array}$ & Total & $\begin{array}{l}\% \text { de la } \\
\text { varianza }\end{array}$ & $\begin{array}{c}\% \\
\text { acumulado } \\
\end{array}$ & Total & $\begin{array}{c}\% \text { de la } \\
\text { varianza }\end{array}$ & $\begin{array}{c}\% \\
\text { acumulado }\end{array}$ \\
\hline 1 & 40,573 & 76,552 & 76,552 & 40,573 & 76,552 & 76,552 & 23,619 & 44,563 & 44,563 \\
\hline 2 & 3,606 & 6,804 & 83,356 & 3,606 & 6,804 & 83,356 & 11,798 & 22,261 & 66,824 \\
\hline 3 & 2,842 & 5,362 & 88,719 & 2,842 & 5,362 & 88,719 & 10,721 & 20,229 & 87,053 \\
\hline 4 & 1,025 & 1,935 & 90,653 & 1,025 & 1,935 & 90,653 & 1,908 & 3,600 & 90,653 \\
\hline 5 & 0,671 & 1,265 & 91,919 & & & & & & \\
\hline 6 & 0,452 & 0,854 & 92,772 & & & & & & \\
\hline 7 & 0,379 & 0,716 & 93,488 & & & & & & \\
\hline 8 & 0,295 & 0,556 & 94,045 & & & & & & \\
\hline 9 & 0,268 & 0,506 & 94,550 & & & & & & \\
\hline 10 & 0,235 & 0,444 & 94,994 & & & & & & \\
\hline
\end{tabular}

Fuente: Elaboración propia.

La matriz de carga factorial, indica el grado de correspondencia entre las variables (es decir cada uno de los 53 días) y los factores, los cuales ya se presentan rotados. Como se sabe en $\mathrm{ACP}$, lo ideal es que cada variable posea un peso alto en un factor y bajo en 
los demás, facilitando la interpretación (y parsimonia) de los factores. Podemos decir que la mayoría de los días son asignados al componente rotado 1 (RPC1), y que ninguno carga al RPC4. Esto implica que este último factor es meramente complementario, lo cual se verá mejor explicado en los mapas de componentes rotados. Para construir cada factor lo que se hace matemáticamente es una suma de cada día multiplicada por el valor de cada carga factorial. Siendo el primer factor rotado $« 0,830^{*} 04$ de enero $+0,778 * 08$ de enero+ 0,662*09 de enero $+\ldots \ldots . .+0,861 * 26$ de diciembre» para cada uno de los 1.800 píxeles.

Los mapas de componentes principales rotados (ver Figuras $N^{\circ} 9$ y $N^{\circ} 10$ ) muestran los patrones espaciales que finalmente serán interpretados. Es conveniente recordar que ellos explican el $90,65 \%$ de la varianza total. Cada uno de ellos será interpretado en concomitancia con las distribuciones de las puntuaciones de cada factor (previamente rotado) en el espacio, lo cual no necesariamente implica que valores altos se relacionen con mayor temperatura. Las configuraciones de los factores rotados se nominan de la siguiente manera:
- RPC1 (ver Figura No 9). Isla de calor urbana asociada a la cuña de las actividades industriales. Gran parte de la ciudad muestra valores altos de esta componente, pero, sin duda, es mayor en las comunas más ligadas a actividades industriales, localizadas de modo contiguo a la Panamericana, al norte de la comuna de Santiago, generando una dorsal que alcanza gran parte de la comuna de Colina.

- RPC2 (ver Figura No 9). Isla de calor del piedmont y cuña de población de altos ingresos económicos. El piedmont de la ciudad (entre Pirque y Colina al norte), además de las laderas de los cerros aislados y la cordillera de la Costa, muestran valores altos del factor, al igual que las comunas donde se localizan las actividades de servicios, oficinas y la población de mayores ingresos económicos (Providencia, Las Condes, Vitacura). La mayor presencia de esta configuración es en el invierno, justamente cuando las brisas montaña valle se hacen más importantes.

- RPC3 (ver Figura No10). Situaciones sin isla de calor urbana. Este factor indica que sus valores máximos y los de las temperaturas en el interior de la ciudad son notoriamente menores a los del sec-

Figura $N^{\circ} 9$

Mapas de los factores 1 y 2 derivados del análisis de componentes principales
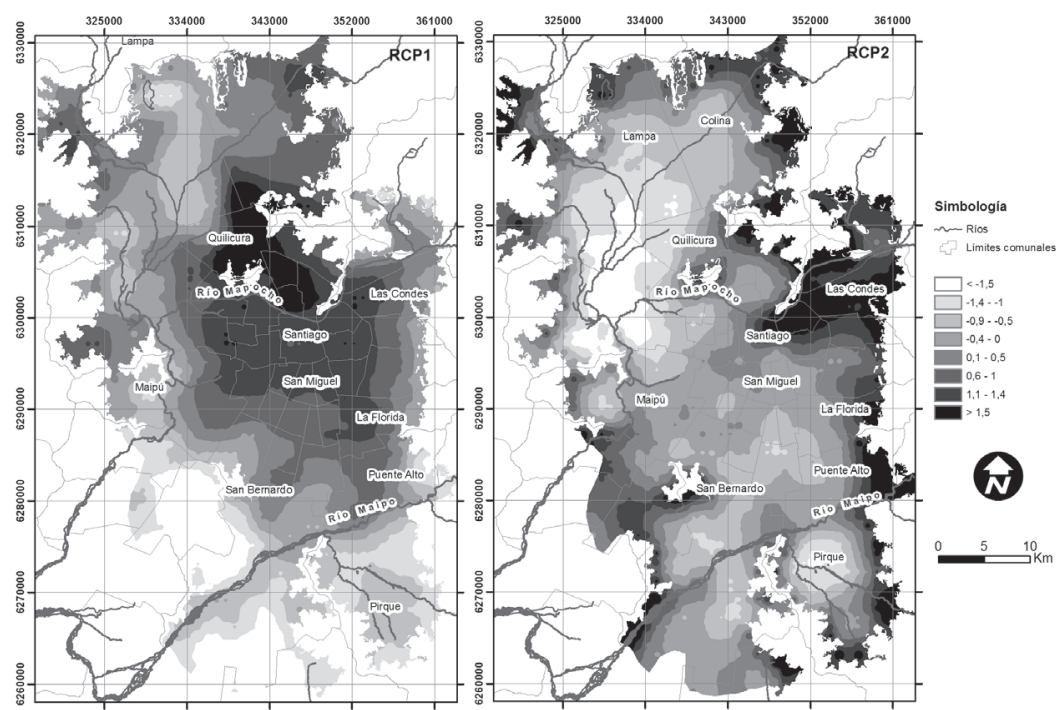

Fuente: Elaboración propia. 
tor periférico del sur y poniente, lo que, pese a ocurrir en pocos días distribuidos en todas las estaciones del año, no posee una variable que permita explicarlos (se ha revisado causas asociadas a los vientos regionales, circulación sinóptica, temperatura, humedad, nubosidad y nieblas).
- RPC4 (ver Figura No 10). Situación complementaria a los componentes principales rotados RPC1 y RPC2, es decir, bajo presencia de isla de calor urbana de superficie. Destaca el sur con una dorsal térmica y zonas más cálidas que la zona oriente de la ciudad, mientras que las comunas del norte se muestran mucho más frías.

Figura $\mathrm{N}^{\circ} 10$

Mapas de los factores 3 y 4 derivados del análisis de componentes principales
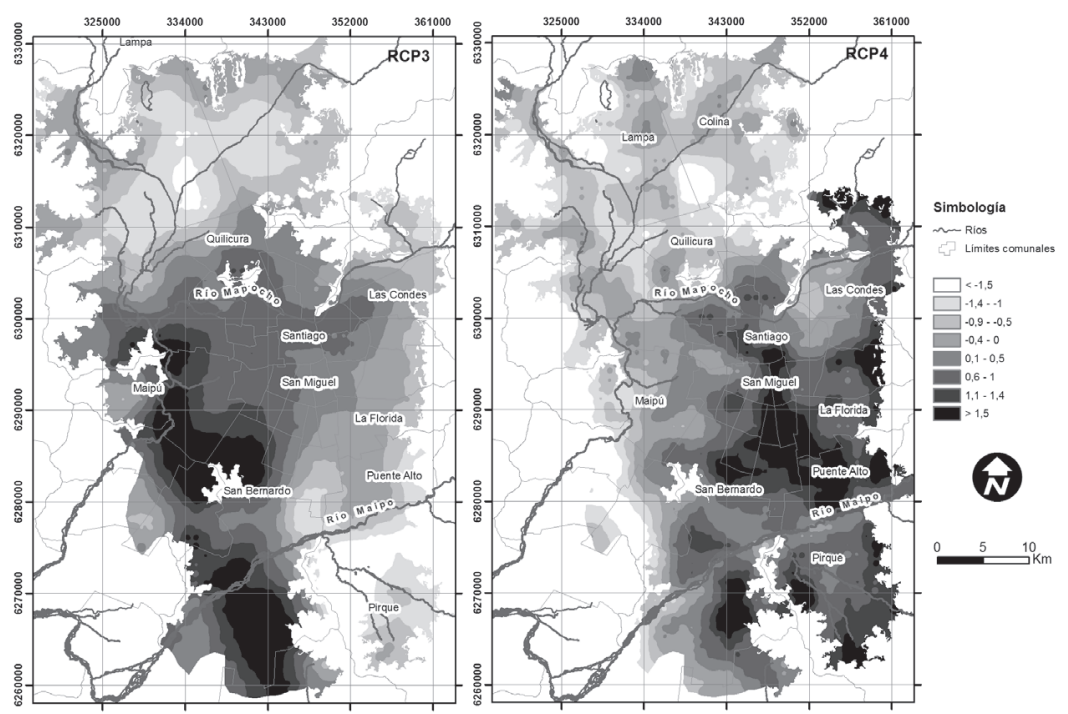

Fuente: Elaboración propia.

\section{Islas de Calor Urbana de Superficie del Área Metropolitana de Santiago}

Una de las hipótesis de la investigación señala que "el uso de la teledetección a una resolución espacial moderada es un procedimiento adecuado para el análisis y la caracterización espacial y temporal de la ICUs", lo que ciertamente se ha comprobado. Esto es así porque la teledetección permite un adecuado número de observaciones en una ciudad del tamaño del Área Metropolitana de Santiago de Chile. Efectivamente, son 1.800 observaciones puntuales, algo que sin duda es una cobertura densa, e imposible de conseguir a costos razonables a través de otros métodos, como transectos en automóvil o una red de estaciones fijas. No obstante, no es una escala adecuada para observar los cañones urbanos. Es decir, su resolución de 1 $\mathrm{km}$ permite cartografiar patrones de la isla de calor, tal y como se consigue con menor precisión con transectos o datos de observatorios meteorológicos, pero no así los microclimas urbanos, que sí se consigue con imágenes Terra ASTER. A continuación, en la Figura $N^{\circ} 11$ se muestra un ejemplo con estas imágenes en Santiago para una madrugada de 2006 (Sarricolea, 2010). Es posible apreciar en la figura que las calles se muestran más cálidas, y que existe consistencia con los resultados de Terra MODIS.

La ciudad presenta la ICUs en las áreas más densamente construidas, y también en aquellas dedicadas a actividades industriales. Además, en la Figura $N^{\circ} 12$, de resolución 90 $\mathrm{m}$, prácticamente todos los cañones urbanos 
de la ciudad son más cálidos que su entorno, tal como dice Eliasson (1994). Las áreas rurales se presentan más frías que la ciudad, con algunas excepciones, y los cursos de agua en la fecha de la observación también son más cálidos.

No obstante, hay asuntos referidos a la distribución de las temperaturas que aún no se han explicado de manera óptima. Uno de ellos tiene relación con patrones no esperados, y que, además, poseen una persistencia notable tanto en espacio como el tiempo. Nos referimos al efecto que las laderas del norte ejercen sobre las temperaturas de emisión superficial, alcanzando valores próximos al centro urbano.

\section{Figura $N^{0} 11$}

Temperatura de emisión superficial a las 0:00 a. m. del día 28/04/2006, usando sensor Terra ASTER.

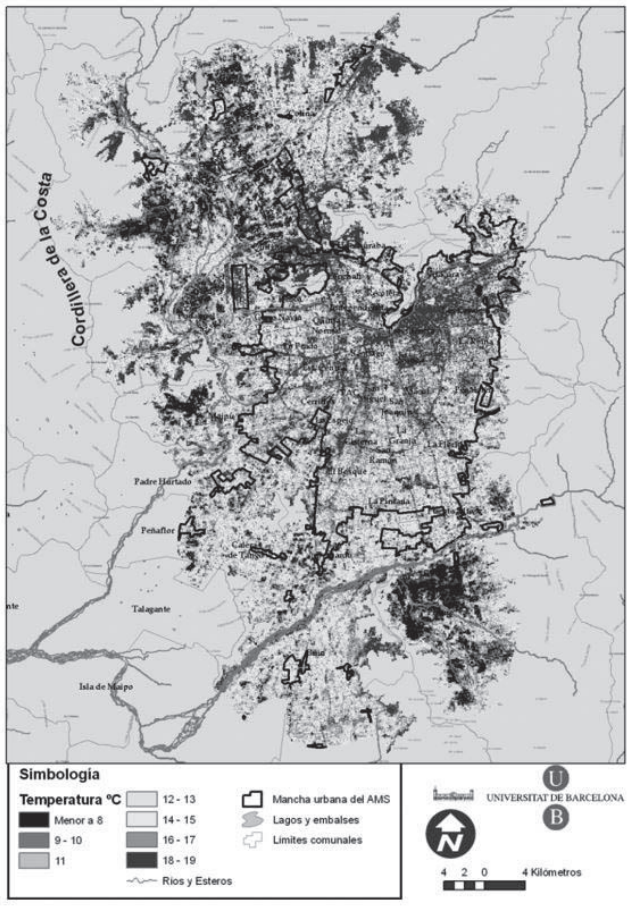

Fuente: Sarricolea (2010)

Más aún, las áreas del poniente en algunas noches también se presentan más cálidas que la ciudad, tal como confirma el ACP en su factor rotado RPC3. Una posible hipótesis que aquí proponemos es la retroalimentación del calor por efecto sumidero y la suma de las brisas campo-ciudad y la catabática. Esto se puede apreciar esquemáticamente en la Figura $\mathrm{N}^{0} 12$, la cual muestra que la brisa de la cordillera de los Andes barre la ICU, y es relocalizada al poniente de la ciudad. El efecto sumidero de calor o «urban heat sink» (Carnahan y Larson, 1990) es similar a lo encontrado en la mañana para Santiago de Chile por Peña (2008), pero en nuestro caso es constatado en la noche, y asumiendo la convección de calor en el centro y su redistribución a la periferia poniente, lo que en días de contaminación por material particulado (PM10) tendría efectos nocivos sobre la salud de esta población.

Para conocer de mejor manera la configuración de la isla de calor es fundamental contar con un buen modelo de los vientos, lo cual ya ha sido enunciado por Cuadrat et al. (2003 y 2005). Por ello, se propone generar en el futuro un modelo mesoescalar de vientos, similar al existente para Chile-Central, pero con la novedad de incorporar la parametrización del efecto urbano, tal como lo expone Martilli (2010) en el caso de Madrid. Por lo tanto, se espera desarrollar para Santiago un modelo que permita mejorar el conocimiento del comportamiento del viento a las 0:00 a. m., pues el nivel de detalle actual es el que se muestra en la Figura $N^{0} 13$.

Respecto a la estacionalidad de la isla de calor, se han encontrado resultados inversos a los de la ciudad de Seúl (Kim y Baik, 2002), es decir, en promedio la máxima intensidad de la ICUs en Santiago es más alta en verano y otoño, siendo relativamente débil en primavera e invierno. Esto puede deberse a que el calor antropogénico a la latitud de Santiago $\left(33^{\circ} 30^{\prime} S\right)$ no suele superar el aporte energético de la radiación solar, a excepción del sector oriente, donde debe ser importante el uso de sistemas de calefacción y aire acondicionado por los hogares y las abundantes oficinas y actividades comerciales.

En la Figura No 14 llama la atención que el método de clasificación automática de situaciones sinópticas de Jenkinson y Collison (J\&C) arroje 5 días de tipo ciclónico, para el conjunto de días analizado, de los cuales 4 son de ICUs muy fuerte (Sarricolea et al., 2014). Revisando los tipos de tiempo ciclónicos y 
Figura $\mathrm{N}^{0} 12$

Esquema hipotético de días de débil o nula ICU en la ciudad y sector poniente más cálido.

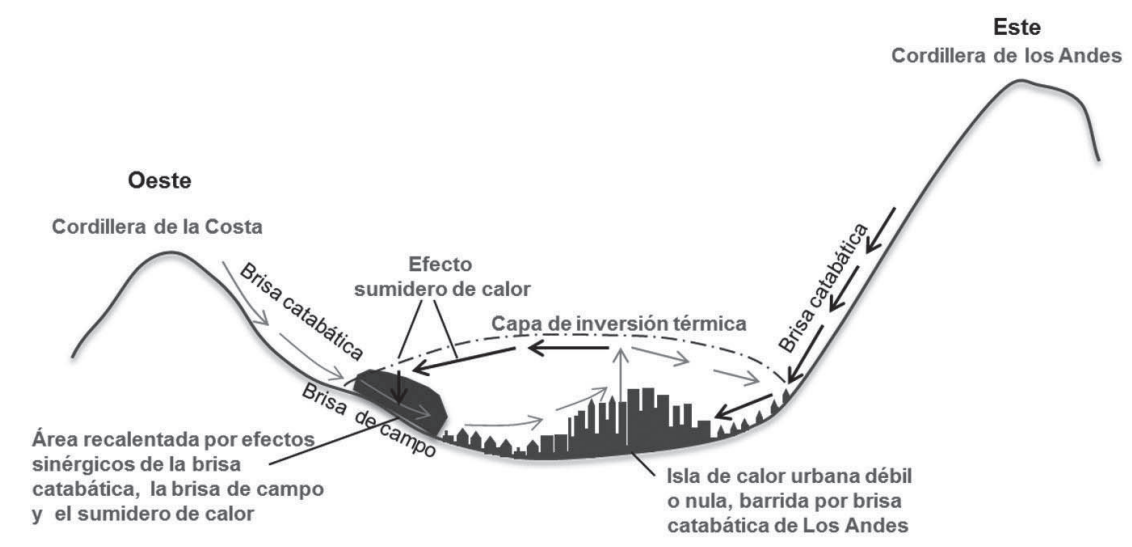

Fuente: Elaboración propia.

Figura $\mathrm{N}^{\mathrm{0}} 13$

Dirección y velocidad del viento del 11 de abril de 2012 a las 0:00 a.m. Dominio de mayor detalle para Chile Central.

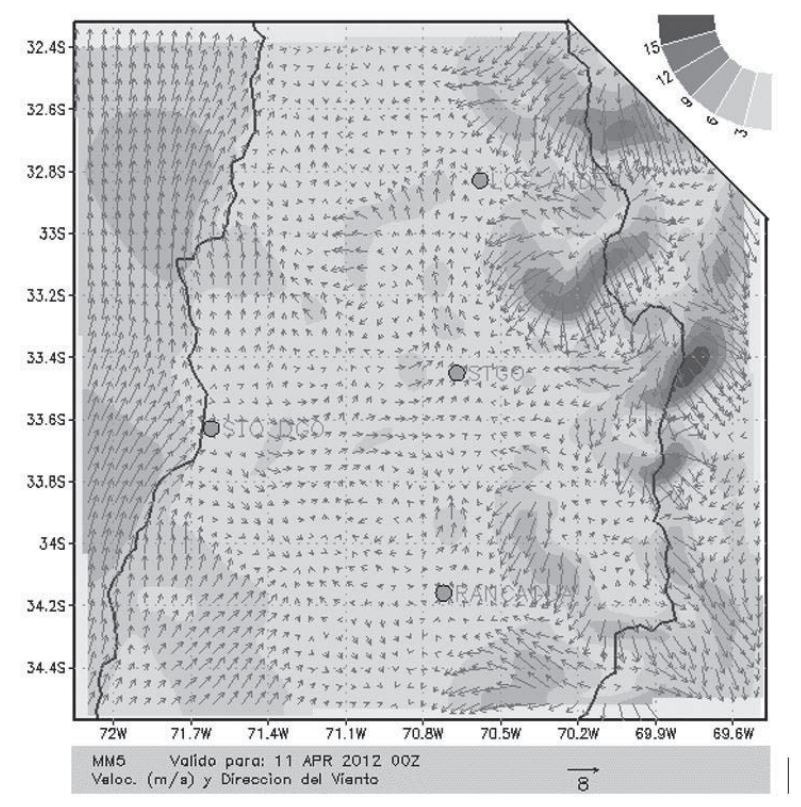

Fuente: Dirección Meteorológica de Chile. Disponible en internet: http://www.meteochile.cl/modeloMM5dominio3_c.html.

sus híbridos nos encontramos con días de temperaturas superiores a $26^{\circ} \mathrm{C}$, lo cual implica que son bajas térmicas. A su vez, los días de ICUs moderada se corresponden con días con altas térmicas (situaciones anticiclónicas de invierno). 
Figura $\mathrm{N}^{0} 14$

Número de días analizados con Terra MODIS según tipo de tiempo de J\&C y categorías de ICUs.

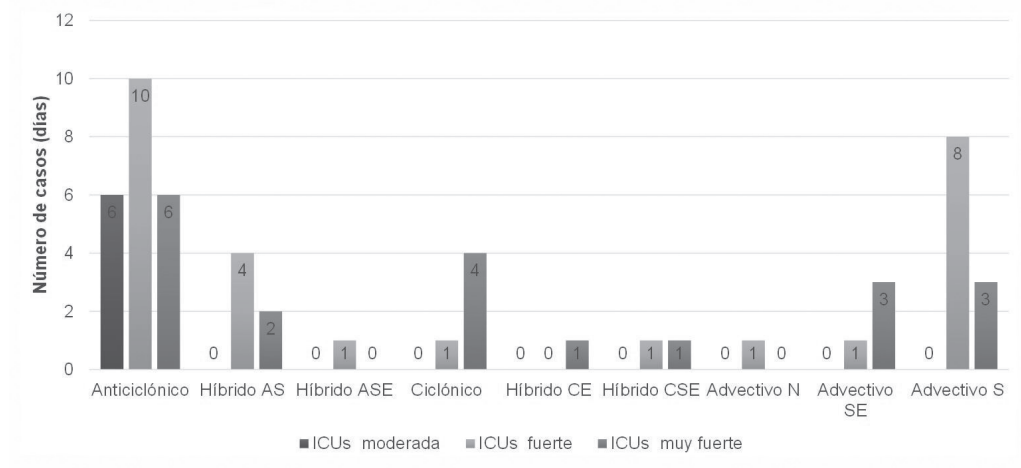

Fuente: Elaboración propia.

\section{Conclusiones}

Los sensores de moderada resolución en ciudades como Santiago son muy adecuados, más aún al ser procesadas sus imágenes mediante Sistemas de Información Geográfica, lo que mejora bastante su calidad gráfica para el estudio de la ICUs.

En especial, las imágenes Terra MODIS vienen listas para ser procesadas, son de resolución diaria y gratuitas. Por lo tanto, permiten caracterizar espacial y temporalmente la isla de calor. El único inconveniente que poseen es el hecho de no registrar la temperatura superficial en días nublados. No obstante, como la ICUs es un fenómeno estructural del clima urbano, una muestra de días despejados es suficiente para caracterizarla.

La isla de calor urbana de superficie y el máximo térmico de la ciudad de Santiago se localizan, efectivamente, en la zona más densamente construida. Sin embargo, también coincide con la zona industrial de Quilicura. Es decir, la hipótesis se confirma, pero se debe precisar que tanto las zonas más densamente construidas, como las industriales, de Santiago poseen una marcada ICUs.

La intensidad de la isla de calor urbana de superficie es de mayor magnitud durante el otoño $\left(7,4^{\circ} \mathrm{C}\right)$, seguida de verano $\left(5,9^{\circ} \mathrm{C}\right)$, primavera $\left(5,4^{\circ} \mathrm{C}\right)$ e invierno $\left(5,0^{\circ} \mathrm{C}\right)$, y con un máximo en los barrios donde se localiza la población de mayores ingresos económicos. Pero las áreas verdes mitigan su intensidad, incluso el albedo de dicha zona, que es más bajo en comparación con el resto de la ciudad.

El análisis de componentes principales revela cuatro patrones típicos de ICUs, que explican el 90,6\% de las situaciones, a saber: ICUs consolidada (44,5\%), ICUs del piedmont y cuña de altos ingresos $(22,3 \%)$, un tipo sin isla de calor urbana $(20,2 \%)$ e ICUs más intensa al sur (3,6\%).

De las situaciones sin isla de calor, se ha sugerido la hipótesis de efecto sumidero de calor o «urban heat sink», asociado a fuerte brisa de la cordillera de los Andes, que barre la ICUs y la desplaza al poniente de la ciudad, lo que en días de contaminación por material particulado (PM10) tendría efectos nocivos sobre la salud de la población de esa parte de la ciudad.

\section{Referencias bibliográficas}

ARNFIELD, J. Two Decades of Urban Climate Research: A Review of Turbulence, Exchanges of Energy and Water, and the Urban Heat Island. International Journal of Climatology, 2003, Vol. 1, № 23, p. 1-26.

CARNAHAN, W. \& LARSON, R. An analysis of an urban heat sink. Remote Sensing of Environment, 1990, Vol. 33, p. 65-71. 
CATTELL, R. The screen test for the number of factors. Multivariate Behavioral Research, 1966, Vol. 1, p. 245-276.

CHEVAL, S. \& DUMISTRECU, A. The July urban heat island of Bucharest as derived from MODIS images. Theoretical and Applied Climatology, 2009, Vol. 96, p. 145-153.

CLINTON, N. \& GONG, P. MODIS detected surface urban heat islands and sinks: Global locations and controls. Remote Sensing of Environment, 2013, Vol. 134, p. 294-304.

CUADRAT, J.; SAZ, M. \& VICENTE-SERRANO, S. Surface wind direction influence on spatial patterns of urban heat island in Zaragoza (Spain). Geophysical Research Abstracts, 2007, Vol. 5, s/p.

CUADRAT, J.; VICENTE-SERRANO, S. \& SAZ, M. Los efectos de la urbanización en el clima de Zaragoza (España): La Isla de Calor y sus factores condicionantes. Boletín de la A.G.E., 2005, № 40, p. 311-327.

ELIASSON, I. Urban-suburban-rural air temperature differences related to street geometry. Physical Geography, 1994, Vol. 15, p. $1-22$.

JIN, M. \& SHEPHERD, J. Inclusion of urban landscape in a climate model. How can satellite data help? Bulletin of the American Meteorological Society, 2005, Vol. 86, № 5, p. 681-689.

JOHNSON, D. Urban modification of diurnal temperature cycles in Birmingham, U.K. International Journal of Climatology, 1985, Vol. 5, p. 221-225.

KAISER, H. The Varimax criterion for analytic rotation in factor analysis. Psychometrika, 1958, Vol. 23, p. 187-200.

KAISER, H. The application of electronic computers to factor analysis. Educational and Psychological Measurement, 1960, № 20, p. 141-151.

KARL, T.; DIAZ, H. \& KUKLA, G. Urbanization: Its Detection and Effect in the United States Climate Record. Journal of Climate, 1998, Vol. 1, p. 1099-1123.
KIM, Y. \& BAIK, J. Maximum Urban Heat Island Intensity in Seoul. Journal of Applied Meteorology, 2002, N41, p. 651-659.

KUKLA, G.; GAVIN, J. \& KARL, T. Urban Warming. Journal of Climate and Applied Meteorology, 1986, №25, p. 1265-1270.

MARTILLI, A. Modelización del clima urbano a mesoecala. Madrid: AEC, 2010.

NICHOL, J. A GIS-based approach to microclimate monitoring in Singapure's highrise housing estates. Photogrammetric Engineering and Remote Sensing, 1994, № 60, p. 1225-1232.

OKE, T. \& VOOGT, J. Complete urban surface temperatures. Journal of Applied Meteorology, 1997, Vol. 9, №36, p. 1117-1132.

PEÑA, M. Relationships between remotely sensed surface parameters associated with the urban heat sink formation in Santiago, Chile. International Journal of Remote Sensing, 2008, Vol. 29, N 15, p. 4385-4404.

RAJASEKAR, U. \& WENG, Q. Urban heat island monitoring and analysis using a nonparametric model: A case study of Indianapolis. Journal of Photogrammetry and Remote Sensing, 2008, № 64, p. 86-96.

ROMERO, H.; IRARRÁZAVAL, F.; OPAZO, D.; SALGADO, M. \& SMITH, P. Climas urbanos y contaminación atmosférica en Santiago de Chile. EURE, $2010 \mathrm{a}$, Vol. 36, № 109, p. 35-62.

ROMERO, H.; SALGADO, M. \& SMITH, P. Cambios climáticos y climas urbanos: Relaciones entre zonas termales y condiciones socioeconómicas de la población de Santiago de Chile. Revista INVI, 2010b, Vol. 25, N 70, p. 151-179.

SARRICOLEA, P. Climatología urbana mediante el uso de la teledetección: aportaciones a la planificación territorial y gestión ambiental del área metropolitana de Santiago. Barcelona: Universitat de Barcelona, Departamento de Geografía Física y A.G.R. Barcelona, 2010.

SARRICOLEA, P.; MESEGUER-RUIZ, O. y MARTÍN-VIDE, F. Variabilidad y tendencias 
climáticas en Chile central en el período 1950-2010 mediante la determinación de los tipos sinópticos de Jenkinson y Collison. Boletín de la A.G.E., 2014, Nº 64, p. 227-247.

SCHWARZ, N.; LAUTENBACH, S. \& SEPPELT, R. Exploring indicators for quantifying surface urban heat islands of European cities with MODIS land surface temperatures. Remote Sensing of Environment, 2011, Vol. 115, No 12 , p. 3175-3186.

SCHWARZ, N.; SCHLINK, U.; FRANCK, U. \& GROBMANN, K. Relationship of land surface and air temperatures and its implications for quantifying urban heat island indicators-An application for the city of Leipzig (Germany). Ecological Indicators, 2012, N ${ }^{\circ}$ 18, p. 693-704.

STEWART, I. \& OKE, T. Classifying urban climate field sites by "local climate zones": The case of Nagano, Japan. In: Seventh International Conference on Urban Climate, June 29 - July 3 of 2009, Yokohama.

STREUTKER, D. Satellite-measured growth of the urban heat island of Houston, Texas. Remote Sensing of Environment, 2003, Vol. 85, p. 282-289.
TOROK, S.; MORRIS, C.; SKINNER, C.; \& PLUMMER, N. Urban heat island features of southeast Australian towns. Australian Meteorological Magazine, 2001, № 50, p. 1-13.

VOOGT, J. \& OKE, T. Thermal Remote Sensing of Urban Climates. Remote Sensing of Environment, 2003, No 86, p. 370-384.

WAN, Z. Collection-5. MODIS Land Surface Temperature Products Users' Guide. Santa Bárbara: ICESS, 2007. Disponible en internet: http://www.icess.ucsb.edu/modis/LstUsrGuide/MODIS_LST_products_Users_guide_C5.pdf

WELLER, J. \& THORNES, J. An investigation of winter nocturnal air and road surface temperature variation in the West Midlands, UK under different synoptic conditions. Meteorological Applications, 2001, № 8, p. 461-474.

WENG, Q. Thermal infrared remote sensing for urban climate and environmental studies: Methods, applications, and trends. Journal of Photogrammetry and Remote Sensing, 2009, $\mathrm{N}^{\circ} 64$, p. 335-344. 
